\title{
Design of a Percolation Reactor for the Hydrolysis of Lignocellulosic Biomass
}

\author{
Isaac Femi Titiladunayo, Olayinka Ahmed Ibitowa \\ Department of Mechanical Engineering, School of Engineering and Engineering Technology, The Federal University of \\ Technology Akure, Akure, Nigeria \\ Email: ftitiladunayo@yahoo.com
}

How to cite this paper: Titiladunayo, I.F. and Ibitowa, O.A. (2018) Design of a Percolation Reactor for the Hydrolysis of Lignocellulosic Biomass. World Journal of Engineering and Technology, 6, 874-884. https://doi.org/10.4236/wjet.2018.64058

Received: September 27, 2018

Accepted: November 19, 2018

Published: November 22, 2018

Copyright ( 92018 by authors and Scientific Research Publishing Inc. This work is licensed under the Creative Commons Attribution International License (CC BY 4.0).

http://creativecommons.org/licenses/by/4.0/

(c) (i) Open Access

\begin{abstract}
A Percolation reactor for the thermochemical pre-treatment of lignocellulosic biomass as a precursor for the production of biofuel such as bioethanol from complex organic polymers is developed by this study. The reactor is designed to hold $3 \mathrm{~kg}$ of pulverised biomass of $0.5 \leq$ and $\geq 0.3 \mathrm{~mm}$ particle size for each hydrolysis run, while the mass of other biomass is determined on the basis of density. It consists of a perforated material holding basket which is $0.0261 \mathrm{~m}^{3}$ in volume, a circulation pump with a power rating of $1.83 \mathrm{~W}$ capacity and a heating chamber containing $3 \mathrm{~kW}$ heater. The reactor is designed to operate within the temperature range of $20^{\circ} \mathrm{C}-180^{\circ} \mathrm{C}$, pressure $\leq 45 \mathrm{~N} \cdot \mathrm{m}^{-2}$, and desired hydrolysis flow rate of $4.33 \times 10^{-4} \mathrm{~m}^{3} \cdot \mathrm{S}^{-1}$. The Percolation reactor produced high sugar yield with instant discharge of sugar products after each completed hydrolysis cycle, thus minimizing sugar decomposition. The efficiency of the percolation reactor was determined to be $64.4 \% \pm 2 \%$ in the hydrolysis of biomass such as cassava peelings to simple sugar. The reactor is therefore a useful tool at converting lignocellulosic biomass to fermentable sugar with high sugar concentration in solid/liquid ratio.
\end{abstract}

\section{Keywords}

Lignocellulosic Biomass, Percolation Reactor, Bioethanol,

Biodegradation, Catalyst

\section{Introduction}

Biofuels (bioethanol) can be produced from biomass feedstocks that are rich in simple sugar such as sucrose, fructose and galactose (e.g. sugarcane) and starchy materials such as plant grain and tubers through direct biodegradation process called fermentation. The use of food crops for fuel production is said to compete 
with food security; leaving researchers with the option of utilising lignocellulosic biomass with complex organic structures for conversion to fuels ethanol through biological processes. The crops that are categorized as lignocellulosic biomass include maize husk, cassava peelings, wheat straws, guinea corn husk, rice husk, millet husk, sawdust and sorghum plant, which cannot be converted directly to bioethanol but have to undergo the process of chemical hydrolysis to convert their complex organic content to fermentable simple sugar. The provision of an adequate environment and pre-conditions for enabling chemical hydrolysis of these biomass wastes for biofuel production e.g. bioethanol is the object of this work. Hence, a percolation reactor is developed for the thermochemical degradation of the cellulose, hemicellulose and the lignin structure of biomass wastes to fermentable sugars.

Many researchers have reported on the use of various reactor such as Stir-tank, Plug flow and Batch reactors for the hydrolysis of biomass. Batch reactor has been the most widely used in the kinetic study of hydrolysis and laboratory study of bioethanol derived therefrom [1]. However, [2], reported the use of percolation reactor in an integrated biorefinery using a dried distillers' grains with an achievement of high pentose yield in a liquid re-circulation process. This research work therefore explored the design of a percolation reactor in preference to others in view of its advantages at reducing acid consumption, promoting higher yield of hemicellulose sugars and lowering the yield of sugar degradation products [3] [4]. Furthermore, unlike the batch and plug flow reactors, the designed percolation reactor does not require solid or liquid separation interface as the solid particles placed in the percolation baskets, do not flow with the liquid as in other reactors. Also, the temperature of the designed percolation reactor is monitored by a thermocouple and controlled by a temperature controller. Hence, the entire process is monitored and maintained at pre-set values. Therefore, damages due to particle attrition are minimal in this reactor as compared to other types of reactors.

The percolation reactor is a packed-bed flow-through reactor. This reactor is tubular and it is filled with solid catalyst particles, most often used to catalyse gas reactions. The chemical reaction takes place on the surface of the catalyst. The advantage of using a packed bed reactor is the higher conversion per weight of catalyst than other catalytic reactors. There are certain advantages in this reactor in comparison to batch and plug flow reactors for hydrolysis of lignocellulosic materials. Lower sugar decomposition can result, since the sugar product is removed immediately after formation in this reactor. A high concentration of sugar can be produced by using a percolation reactor, since a high solid/liquid ratio can be used and also mass transfer between the liquid medium and solid catalyst is facilitated at high liquid flow rate. Furthermore, unlike the batch and plug flow reactors, this process does not need a solid or liquid separation [4] as the solid are placed in the percolation baskets and do not flow with the liquid. Damages due to particle attrition are minimal in this reactor when compared to 
other types of reactor. In a study by the National Renewable Energy Laboratory (NREL) in the USA, a continuously flowing, two-stage percolation reactor resulted in more than $95 \%$ of the theoretical yield of solubilized xylose sugars (monomeric and oligomeric) from yellow poplar sawdust [5]. Percolation reactors were used in most of the old wood sugar processes such as the Scholler process, the Madison wood sugar process, and some of the Soviet processes [4].

\section{Materials and Methods}

The percolation reactor Figure 1 consists of two concentric cylinders made from $3 \mathrm{~mm}$ galvanised steel plate. The inner cylinder has a diameter and a height of $270 \mathrm{~mm}$ and $456 \mathrm{~mm}$ respectively, while the outer cylinder has a diameter of 370 $\mathrm{mm}$ and height of $456 \mathrm{~mm}$. Mild steel was selected for the design because it is available, cheap, corrosion resistant and could withstand high temperature. A 50 $\mathrm{mm}$ thick fibreglass was used as a lagging material and sandwiched between the two cylinders to prevent heat loss and gain in the reactor chamber. A discharge outlet is incorporated into the reactor for the collection of hydrolysed sugar at various predetermined intervals. The base of the reactor chamber is made conical in shape for easy discharge of hydrolyzate after hydrolysis and cleaning after use.

The perforated basket holding the feedstock in the reactor for hydrolysis has a mesh size of 297 microns and sits directly inside the inner cylinder. However, it could be moved or put in place as required through installed handles. A heating compartment through which the hydrolyzate circulates is attached to the reactor and powered by a $3000 \mathrm{~W}$ heating element. The temperature of the component is controlled and regulated by a type- $\mathrm{K}$ thermocouple and a temperature controller

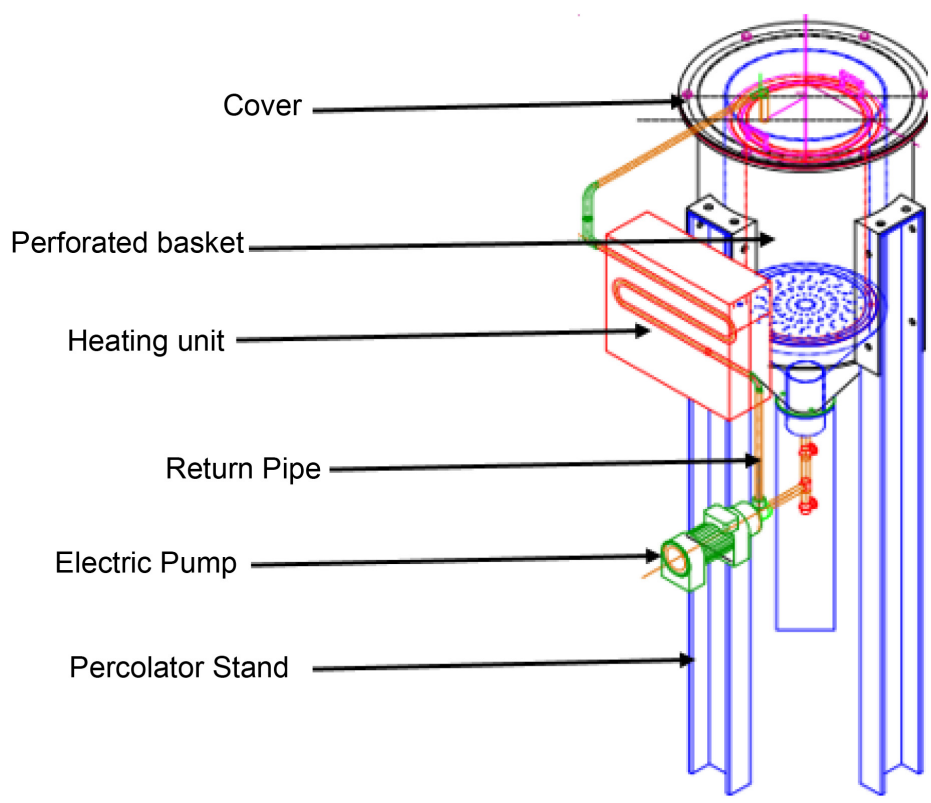

Figure 1. Percolation reactor with liquid recirculation used for biomass hydrolysis. 
at desired set points. The rate of hydrolyzate circulation and pressure is controlled by a variable speed pump of $1.83 \mathrm{~W}$ capacity. A control box that superintends and monitors the entire operation of the percolation reactor is designed and incorporated into the reactor. The reactor operates by receiving materials into the hydrolysis basket, generate hydrolyzates by circulating heated water with dilute acids at pre-set temperature, pressure and constant flowrate. Heat supply to the reactor is reliable and rapid while heat loss is very minimal.

\section{Design Considerations for the Percolation Reactor}

The following design considerations influenced the design of the percolation reactor for the acid hydrolysis of lignocellulosic biomass wastes.

\subsection{Volume of Reactor Chamber $\left(V_{i}\right)$}

The volume of the reaction chamber was determined to be $0.026 \mathrm{~m}^{3}$ (26 ltrs) using Equation (1) as proposed by [6]. The reactor chamber is the inner component of the machine where the homogenization of reactant takes place.

$$
V_{i}=\frac{\pi}{4} D_{i}^{2} l_{i}
$$

where:

$V_{i}$ is the reactor volume;

$D_{i}$ is the inner diameter of the reactor;

$l_{i}$ is the internal length of the reactor.

\subsection{Volume of Reactor's Perforated Basket}

The perforated basket was determined to be $0.0093 \mathrm{~m}^{3}$ (9.3 ltrs) using Equation (2) suggested by [6]

$$
V_{b}=\frac{\pi}{4} D_{b}^{2} l_{b}
$$

where:

$V_{b}$ is the perforated basket volume;

$D_{b}$ is the diameter of the perforated basket;

$l_{b}$ is the depth of perforated basket.

\subsection{Volume of Feedstock Required for Hydrolysis with a Known Mass of Feedstock}

The volume of feedstock mixture $\left(V_{m}\right)$ charged into the reactor was determined to be $0.0053 \mathrm{~m}^{3}$ (5.3 ltrs) using Equation (3).

$$
\begin{gathered}
V_{m}=\text { Volume of biomass }+ \text { Volume of water } \\
\text { Volume of substance }\left(V_{m}\right)=\frac{\text { Mass of Substance }}{\text { Density of Substance }}
\end{gathered}
$$

\subsection{Heat Gained by Water to Change Phase from Liquid to Vapour}

Heat gained by water to change phase $=m l_{v}$ 
where:

$m$ is the mass of water;

$l_{v}$ is the specific latent heat of vapourization;

Heat gained by biomass $=m_{C} C p_{C} \Delta t+m_{W} C p_{W} \Delta t$

where:

$m_{C}$ is the mass biomass;

$C p_{C}$ is the specific heat capacity of biomass;

$\Delta t$ is the change in temperature;

$C p_{W}$ is the specific heat capacity of water;

Total heat gain $=$ heat gained by water to change phase + heat gained by biomass;

Total heat gained = heat supplied by the heating element;

Heat supplied by heating element $=P_{h} t$

$P_{h}$ is the power rating of the heating element;

$t$ is the time in seconds.

According to heater selection and sizing (BTU Electric Heater, 2US) for $220 \mathrm{~V}$ applied voltage, the efficiency of heater voltage is $84 \%$.

Actual rating of heating element $=\frac{\text { Theoretical Power }\left(P_{h}\right)}{\text { Efficency of heater volatge }}$

The actual heat generated by the heating element in 25 minutes is given below

$$
\text { Actual heat generated }\left(Q_{W}\right)=I V t=P_{h} t
$$

\subsection{Determination of Thickness and Type of Insulation}

In order to avoid or reduce heat losses from the mixing chamber through the walls of the reactor from the basket to the inner shell and to the outer shell of the reactor, it is necessary to insulate the vessel with properly selected and sized material. The insulating material was fibre glass, and the choice of fibre glass is that it has high thermal resistivity and it is readily available. Applying Fourier's Equation of heat transfer through conduction,

$$
Q=-\frac{\theta_{1}-\theta_{2}}{\frac{x_{1}}{k_{1} A_{1}}+\frac{x_{2}}{k_{2} A_{2}}}
$$

where:

$Q$ is the calculated rating of the heating element;

$\theta_{1}$ is the temperature of inner shell of the reactor;

$\theta_{2}$ is the temperature of the outer wall of the reactor;

$k_{1}$ is the heat transfer coefficient of steel;

$k_{2}$ is the heat transfer coefficient of fibre glass;

$A_{1}$ is the area of steel plate;

$A_{2}$ is the area to be filled by fibre glass;

$x_{1}$ is the thickness of steel plate; 
$X_{2}$ is the thickness of glass wool.

$$
\begin{gathered}
x_{2}=-k_{2} A_{2}\left(\frac{\theta_{1}-\theta_{2}}{Q}-\frac{2 x_{1}}{k_{1} A_{1}}\right) \\
A=2 \pi r h \\
A_{1}=2 \pi r_{1} h
\end{gathered}
$$

where:

$r_{1}$ is the radius of inner shell of the bioreactor;

$h$ is the height of the reactor from the heat source to the top cover of the vessel.

$$
A_{2}=2 \pi r_{2} h
$$

where:

$r_{2}$ is the radius of shell to be filled with fibre glass;

$h$ is the height of the reactor from the heat source to the top cover of the vessel.

Thickness of insulator $x_{2}=-k_{2} A_{2}\left(\frac{\theta_{1}-\theta_{2}}{Q}-\frac{2 x_{1}}{k_{1} A_{1}}\right)$

The unit is divided into two (inner chamber and out chamber) with the space between filled with the lagging materials (fibre glass), the purpose of lagging material is to reduce heat losses to the minimum level. Fibre glass was considered for the lagging material because it is a poor conductor of heat insulation.

\subsection{Heat Transfer in the Reactor Chamber}

The heat transfer in the reactor chamber is by convection and conduction. Heat is transfer by convection from the cassava peels to the basket, from basket to the inner wall of the reactor chamber, heat transfer is by conduction from inner wall of the reactor chamber to the insulating material and from the insulating material to the outside wall of the reactor and convective heat transfer from the outside wall of the reactor to the surrounding.

Heat transfer from cassava peels at temperature $T_{c}$ to the wall of the reactor basket at temperature $T_{w 1}$ is given in Equation (13)

$$
Q=h A\left(T_{c}-T_{w 1}\right)
$$

Heat transfer from the basket of the reactor at $\left(T_{w 1}\right)$ to the inner material of the reactor at $\left(T_{w 2}\right)$ is given in Equation (14)

$$
Q=\frac{2 \pi K_{m} L\left(T_{w i}-T_{w 2}\right)}{\ln \frac{r_{2}}{r_{1}}} \text { [7] }
$$

Heat transfer from inner material at $\left(T_{w 2}\right)$ to the insulating at $\left(T_{w 3}\right)$ is given in Equation (15)

$$
Q=\frac{2 \pi K_{f} l\left(T_{w 2}-T_{w 3}\right)}{\ln \frac{r_{3}}{r_{2}}}
$$


Heat transfer through the insulating material to the outside wall of the reactor cylinder of thickness $t_{3}$ is given in Equation (16)

$$
Q=\frac{2 \pi K_{m} l\left(T_{w 3}-T_{w 4}\right)}{\ln \frac{r_{4}}{r_{3}}} \text { [7] }
$$

Heat transfer from the outside wall of the reactor to the surrounding atmosphere is given in Equation (17)

$$
Q=h A\left(T_{w 4}-T_{\infty}\right) \text { [7] }
$$

Combining Equations (13)-(17),

$$
Q=\frac{2 \pi L\left(T_{C}-T_{\infty}\right)}{\frac{1}{r_{1} h_{C}}+\frac{\ln \left(r_{2} / r_{1}\right)}{K_{g}}+\frac{\ln \left(r_{3} / r_{2}\right)}{K_{f}}+\frac{\ln \left(r_{4} / r_{3}\right)}{K_{m}}+\frac{1}{r_{4} h_{a}}}
$$

Since $Q$ is known from Equation (18), then substitution into Equation (18) given the interface temperatures $T_{w 1}, T_{w 2}, T_{w 3}$ and $T_{w 4}$

$$
\begin{aligned}
& r_{3}=r_{2}+2 t_{2} \\
& r_{4}=r_{3}+2 t_{3}
\end{aligned}
$$

where:

$Q$ is the heat transferred in the reactor chamber to the surrounding $(\mathrm{kJ} / \mathrm{kg})$;

$l$ is the length of the reactor cylinder;

$h_{a}$ is the convective heat transfer coefficient of air;

$h_{c}$ is the convective heat transfer coefficient of biomass;

$K_{g}$ and $K_{m}$ is the thermal conductivity of galvanised plates and mild steel;

$K_{f}$ is the thermal conductivity fiberglass;

$A$ is the surface area of the reactor cylinder;

$t_{1}$ is the thickness of the perforated basket;

$t_{2}$ is the thickness of the inner cylinder;

$t_{3}$ is the thickness of the fiberglass;

$T_{\infty}$ is the ambient temperature;

$T_{c}$ is maximum temperature of the biomass in the reactor.

\subsection{Pressure in the Bioreactor $\left(P_{R}\right)$}

During the mixture of feedstock within the reactor, pressure is created as a result of the heat generated from the heater which leads to collision of water molecules and the feedstock which built up the pressure with the wall of the reactor chamber. The estimated pressure was calculated using Equation (19)

$$
P_{R}=\frac{F}{A_{i}} \quad[6]
$$

where:

$P_{R}$ is the pressure in the bioreactor;

$A_{i}$ is the internal diameter of the reactor;

$F$ is the force. 


\subsection{Increase in Diameter $\left(\Delta D_{i}\right)$ Due to Internal Pressure}

The increase in internal diameter of the reactor shell due to the internal pressure produced was dertermine using given Equation (20)

$$
\Delta D_{i}=\frac{P_{R} D_{i}}{2 t_{i} E}\left(1-\frac{\mu}{2}\right) \quad[6]
$$

where,

$P_{R}$ is the internal pressure produced in the reactor;

$t_{i}$ is the thickness of plate;

$E$ is the Young modulus of the shell material;

$\mu$ is the poisson ratio of the material ranging.

\subsection{Increase in Length $\left(\Delta I_{i}\right)$ Due to Internal Pressure}

The increase in length of the reactor shell due to the internal pressure produced was calculated using given Equation (21)

$$
\Delta l_{i}=\frac{P_{R} l_{i} D_{i}}{2 t_{i} E}\left(\frac{1}{2}-\mu\right) \quad[6]
$$

where,

$P_{R}$ is the internal pressure produced in the reactor;

$t_{i}$ is the thickness of plate;

$E$ is the Young modulus of the shell material;

$\mu$ is the poisson ratio of the material ranging;

$l_{i}$ is the length of the inner cylinder.

\subsection{Increase in Internal Volume $\left(\Delta V_{i}\right)$ Due to Internal Pressure}

The increase in internal volume $\Delta V_{i}=\frac{\pi}{4}\left(D_{i}+\Delta D_{i}\right)\left(l_{i}+\Delta l_{i}\right)-\frac{\pi}{4} D_{i}^{2} l_{i}$

\subsection{Pump Design}

Density of water mixture is calculated as:

$$
\begin{gathered}
\rho_{w} V_{w}+\rho_{c} V_{c}=\rho_{m} V_{m} \\
\rho_{m}=\frac{\rho_{w} v_{w}+\rho_{c} v_{c}}{v_{m}}
\end{gathered}
$$

The total Power exerted to the mixture at a height of $0.456 \mathrm{~m}$ is:

$$
P_{m}=\rho_{m} g Q H
$$

$$
\text { Flow rate }=Q=\frac{V_{i}}{60 \mathrm{~s}}
$$

\subsection{Pipe Sizing}

The pipe used for the piping of the hydrolyzate from the top of the reactor down to the pump to the heater was made galvanized and they were selected according to ASTM standard to accommodate fouling. 


\section{Results and Discussion}

The wall of the reactor and its height were determined to have increased slightly by $3.022 \times 10^{-9} \mathrm{~m}$ and $1.201 \times 10^{-9} \mathrm{~m}$ respectively, while the change in volume was found to be $8.8 \times 10^{-9} \mathrm{~m}^{3}$. However, the operating temperature and the internal pressure of the circulating hydrolyzate, were largely responsible for the infinitesimal dimensional changes, which the reactor shell could withstand without undue material stress. The results for the design of the percolation reactor are presented in Appendix A and the percolation efficiency was estimated for the hydrolysis of biomass such as cassava peelings using Equation (26);

Percolation Efficiency for hydrolysis of cassava peelings $=\frac{\text { output }}{\text { input }} \times 100 \%$ (26)

Input is the total mass of biomass and acid solution needed for hydrolysis $=$ $2.5 \mathrm{~kg}$.

Output is the mass of cassava peeling hydrolysed $=1.61 \mathrm{~kg}$.

Percolation efficiency for hydrolysis $=\frac{1.61}{2.5} \times 100 \%$.

Percolation Efficiency for hydrolysis $=64.4 \%$.

The percentage efficiency of the percolation reactor for the hydrolysis of cassava peels indicates that the reactor was able to completely hydrolyse the biomass feedstock into simple sugars.

1) Assembly of the Percolation Reactor (Figure 2).

2) Developed Reactor.

The reactor was assembled and placed on a flat surface as shown in Figure 3.

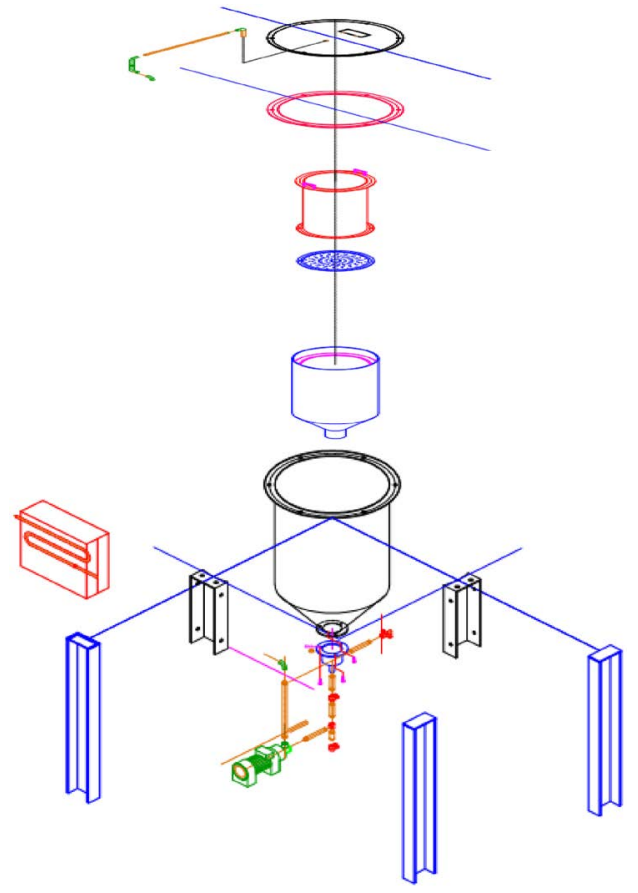

Figure 2. Assembly of the reactor parts. 


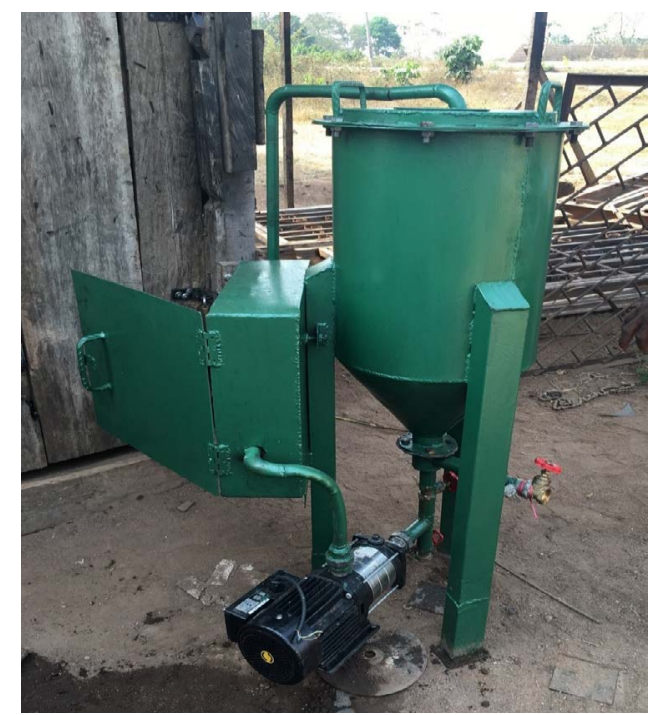

Figure 3. The percolation reactor.

\section{Conclusion}

The percolation reactor was designed and fabricated using locally available materials, while the hydrolysis of lignocellulosic biomass was carried out on it, using cassava peels as feedstock. The efficiency of the percolation reactor for the hydrolysis of cassava peels was estimated to be $64.4 \%$ indicating that the reactor was able to completely hydrolyse the biomass feedstock. The reactor is simple to operate, easy to maintain and affordable.

\section{Conflicts of Interest}

The authors declare no conflicts of interest regarding the publication of this paper.

\section{References}

[1] Brandberg, T., Sanandaji, N., Gustafsson, L. and Franzen, C.J. (2005) Continuous Fermentation of Undetoxified Dilute Acid Lignocellulose Hydrolysate by Saccharomyces cerevisiae ATCC 96581 Using Cell Recirculation. Biotechnology Progress, 21, 1093-101. https://doi.org/10.1021/bp050006y

[2] Dania, A.F., Robert, L., David, T., Mayank, G. and Jagannadh, S. (2014) Towards Integrated Biorefinery from Dried Distillers Grains: Selected Extraction of Pentoses Using dilute Acid Hydrolysis. Biomass and Bioenergy, 71, 178-186.

[3] Yang, B. and Wyman, C.E. (2004) Effect of Xylan and Lignin Removal by Batch and Flow through Pretreatment on the Enzymatic Digestibility of Corn Stover Cellulose. Biotechnology and Bioengineering, 86, 88-95. https://doi.org/10.1002/bit.20043

[4] Lee, Y.Y., Iyer, P. and Torget, R.W. (1999) Dilute-Acid Hydrolysis of Lignocellulosic Biomass. Advances in Biochemical Engineering/Biotechnology, 5, 93-115. https://doi.org/10.1007/3-540-49194-5_5

[5] Torget, R. and Hsu, T.A. (1994) Temperature Dilute-Acid Prehydrolysis of Hardwood Xylan Using a Percolation Process. Applied Biochemistry and Biotechnology, 45, 5-22. https://doi.org/10.1007/BF02941784 
[6] Khurmi, R.S. and Gupta, J.K. (2005) A Textbook of Machine Design. Eurasia Publishing House (PVT) Ltd., New Delhi.

[7] Lienhard IV, J.H. and Lienhard V, J.H. (2006) A Heat Transfer Textbook. 3rd Edition, Phlogiston Press, Cambridge.

\section{Appendix A: Design Parameters for the Design Percolation} Reactor

\begin{tabular}{|c|c|c|c|}
\hline $\mathrm{S} / \mathrm{N}$ & DESIGNS & EQ. USED & RESULT \\
\hline 1 & $\begin{array}{l}\text { Volume of the Reactor } \\
\text { chamber }\end{array}$ & $\frac{\pi}{4} D_{i}^{2} l_{i}$ & $\begin{array}{l}0.0261 \mathrm{~m}^{3} \\
\text { (26 Litres) }\end{array}$ \\
\hline 2 & $\begin{array}{l}\text { Volume of the } \\
\text { perforated basket }\end{array}$ & $\frac{\pi}{4} D_{b}^{2} l_{b}$ & $\begin{array}{l}0.0093 \mathrm{~m}^{3} \\
(9.3 \text { Litres) }\end{array}$ \\
\hline 3 & $\begin{array}{l}\text { Volume of feedstock } \\
\text { required for hydrolysis }\end{array}$ & $V_{C}+V_{W}$ & $\begin{array}{l}0.0053 \mathrm{~m}^{3} \\
(5.3 \text { Litres })\end{array}$ \\
\hline 4 & $\begin{array}{l}\text { Determination of Green } \\
\text { basis of the cassava peels }\end{array}$ & $\frac{W_{C}-D_{C}}{D_{C}} \times 100 \%$ & $60 \%$ \\
\hline 5 & $\begin{array}{l}\text { Heat gained by water to } \\
\text { change phase }\end{array}$ & $m l_{v}$ & $2.256 \times 10^{6} \mathrm{~J} / \mathrm{kg}$ \\
\hline 6 & Heat gained by cassava peels & $M_{C} C p_{C} \Delta t+M_{W} C p_{W} \Delta t$ & $2841.305 \mathrm{~kJ}$ \\
\hline 7 & Heating element rating & $\frac{\text { Theoretical Power }}{\text { Efficency of heater volatge }}$ & $3.1777 \mathrm{~kW}$ \\
\hline 8 & Actual heat generated & $\left(Q_{W}\right)=I V t=P_{h} t$ & $4500 \mathrm{~kJ}$ \\
\hline 9 & $\begin{array}{l}\text { Determination of thickness } \\
\text { and type of insulation }\end{array}$ & $-k_{2} A_{2}\left(\frac{\theta_{1}-\theta_{2}}{Q}-\frac{2 x_{1}}{k_{1} A_{1}}\right)$ & $100 \mathrm{~mm}$ \\
\hline & & $2 \pi l\left(T_{c}-T_{\infty}\right)$ & \\
\hline 10 & $\begin{array}{l}\text { Heat transfer in the reactor } \\
\text { chamber }\end{array}$ & 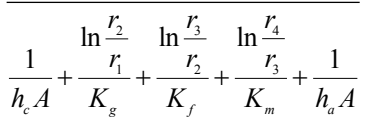 & $0.434 \mathrm{~kJ} / \mathrm{kg}$ \\
\hline 11 & $\begin{array}{l}\text { Pressure in the reactor } \\
\text { chamber }\end{array}$ & $\frac{F}{A_{i}}$ & $38.04 \mathrm{~N} / \mathrm{m}^{2}$ \\
\hline 12 & $\begin{array}{l}\text { Increase in diameter due to } \\
\text { internal pressure }\end{array}$ & $\frac{P_{R} D_{i}}{2 t_{i} E}\left(1-\frac{\mu}{2}\right)$ & $3.022 \times 10^{-9} \mathrm{~m}$ \\
\hline 13 & $\begin{array}{l}\text { Increase in length due to } \\
\text { internal pressure }\end{array}$ & $\frac{P_{R} l_{i} D_{i}}{2 t_{i} E}\left(\frac{1}{2}-\mu\right)$ & $1.201 \times 10^{-9} \mathrm{~m}$ \\
\hline 14 & $\begin{array}{l}\text { Increase in volume due to } \\
\text { internal pressure }\end{array}$ & $\frac{\pi}{4}\left(D_{i}+\Delta D_{i}\right)\left(l_{i}+\Delta l_{i}\right)-\frac{\pi}{4} D_{i}^{2} l_{i}$ & $8.8 \times 10^{-9} \mathrm{~m}^{3}$ \\
\hline 15 & Determination of pump size & $\rho_{m} g Q H$ & $0.5 \mathrm{hp}$ \\
\hline 16 & Pipe sizing & $\begin{array}{l}\text { Selected according to ASTM } \\
\text { standard }\end{array}$ & 1 and $1 \frac{1}{2}$ inch \\
\hline
\end{tabular}

